\title{
Air pollution as a result of the development of motorization
}

\author{
Czech R. ${ }^{1}$, Zabochnicka-Świątek M. ${ }^{2 *}$, Świątek M.K. ${ }^{3}$ \\ ${ }^{1}$ Silesian University of Technology, Akademicka 2A, 44-100 Gliwice, Poland \\ ${ }^{2}$ Czestochowa University of Technology, Faculty of Infrastructure and Environment, Brzeźnicka 60 a, 42-200 Częstochowa, Poland \\ ${ }^{3}$ Medical University of Silesia, Faculty of Medical Sciences in Katowice, Poniatowskiego 15, Katowice, Poland \\ Received: 16/01/2019, Accepted: 04/03/2020, Available online: 18/06/2020 \\ *to whom all correspondence should be addressed: e-mail: magdalena.zabochnicka@pcz.pl \\ https://doi.org/10.30955/gnj.003021
}

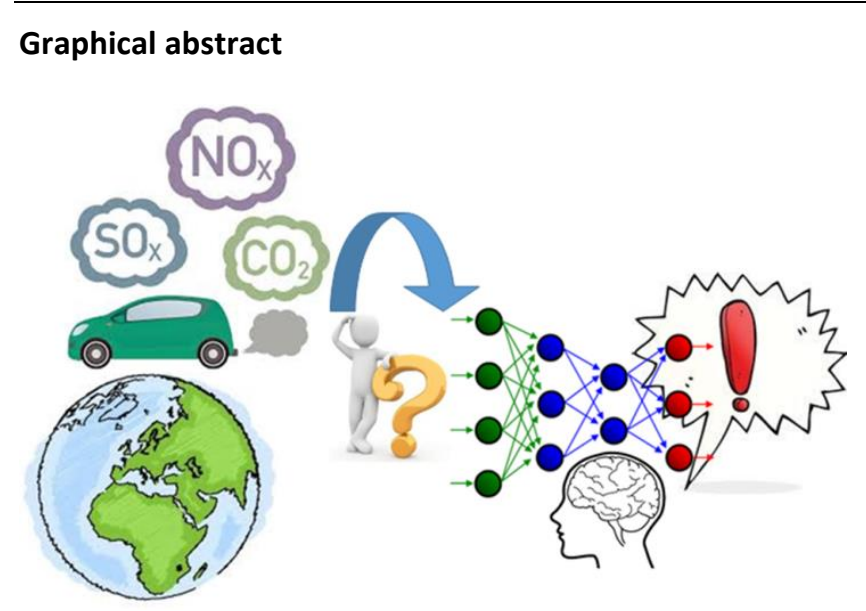

Abstract

The problem of air pollution is one of the most important problems faced by the world in the context of large urban agglomerations. Numerous activities are being undertaken all over the world to both counteract existing pollution and prevent the emergence of another one. Manufacturing is one of the activities that have a significant negative impact on the natural environment. Starting from the production itself, through the life of vehicles, and ending with the problems of storage and recycling of used means of transport, at every stage there are negative effects on the environment. There is no doubt that in all types of proecological activities, it may be extremely important to predict the future state based on various determinants occurring in the analysed or preceding period of time. To this end, various types of mathematical and statistical tools are being used. Recently, you can also notice interest in all types of methods aided by artificial intelligence. Such methods include artificial neural networks, fuzzy logic, or evolutionary algorithms. The article presents the problems of environmental pollution as a result of the development of motorization. The main components of exhaust gases from car engines are discussed, which are particularly harmful to the natural environment. Methods for reducing the emission of pollutants emitted from internal combustion engines are described, and the monitoring of hazards related to air pollution is discussed. The possibilities of using artificial neural networks as a tool for modelling the state of air pollution have also been discussed.

Keywords: Air pollution, automotive, modelling, neural networks.

\section{Introduction}

Intensive development of civilization, with constantly increasing human production and consumption capabilities, leads to increased degradation of the environment. This problem has been noticed many years ago, and the world's largest powers are constantly trying to establish one common world policy to protect the environment from destruction (Krzywonos et al., 2014; Zabochnicka-Świątek, 2015).

One of the basic areas of human activity, which is identified with the environmental degradation activities, is motorization (Chłopek, 2002). Its effects are very clearly felt by people. Automotive industry should be understood here as an increased number of vehicles travelling on the road, but also the production and service activities associated with it.

The natural environment adversely affects, among other vehicles, vehicle factories, parts and consumables factories, industrial and transport infrastructure, consumables used in all stages of the life of the product, which is the vehicle.

The most socially troublesome aspects of motoring are undoubtedly emission of harmful substances to the environment, vibro-acoustic phenomena (vibrations, noise) accompanying the work of machines and moving vehicles, ecological consequences of accidents and related hazards.

Automotive industry adversely affects human, animal and plant health, pollutes air, water, soil, land and landscape. This is an inevitable consequence of the life cycle, which consists of the construction, production, operation and recycling stages. Considering the above, it is necessary to use appropriate methods to monitor the state of air, which will allow predicting the degree of environmental pollution and taking action to minimize the hazards of airborne 
substances harmful to human health, animals and the environment.

It should be noted that currently various tools are used to monitor the state of environmental pollution, including using advanced mathematical methods. Such tools undoubtedly include all types of artificial intelligence methods, including artificial neural networks, fuzzy logic, or genetic algorithms.

The aim of the work was to discuss issues related to air pollution as a result of the development of motorization. This study discusses the main components of exhaust gases from car engines, which are particularly harmful to the natural environment. Methods for reducing the emission of pollutants emitted from internal combustion engines are described, and the monitoring of hazards related to air pollution is discussed. The possibilities of using artificial neural networks as a tool for modelling the state of air pollution have also been discussed. The artificial neural networks are brain-inspired systems which are intended to replicate the way that humans learn. Neural networks consist of input, hidden and output layers, consisting of units that transform the input into something that the output layer can use. They are excellent tools for finding patterns (Hu and Hwang, 2002; Korbicz et al., 2002; Nałęcz et al., 2000; Osowski, 2013; Tadeusiewicz, 1993; Tadeusiewicz et al., 2014).

\section{Toxic components contained in the exhaust}

Basic air pollutants are primary pollutants. They get into the air as a result of emissions from anthropogenic or natural sources. On the other hand, some of them undergo changes which lead to secondary pollution. In other words, primary pollutants are emitted directly from sources, while secondary pollutions arise as a result of changes from primary pollutants. Primary contaminants include $\mathrm{SO}_{2}$, $\mathrm{PM}_{10}, \mathrm{NO}, \mathrm{CO}$, and for secondary $\mathrm{O}_{3}, \mathrm{NO}_{2}$ (Vallero, 2014).

Engine exhaust is a mixture of substances found in various states of matter. To a large extent, substances predominate in the gaseous state of aggregation, but as the temperature of the engine exhaust gases decreases, the share of liquid and solid substances increases (Chłopek, 2002).

The main harmful to the environment and toxic components of engine exhausts include:

- carbon oxides $\mathrm{CO}$,

- Hydrocarbons, $\mathrm{HC}$ and their derivatives,

- nitrogen oxides, $\mathrm{NO}_{\mathrm{x}}$

- sulphur oxides, $\mathrm{SO}_{\mathrm{x}}$

- lead compounds,

- PM solid particles (including soot, fumes, ashes, metals).

In contrast, substances harmful to the environment that favor the formation of the greenhouse effect in the atmosphere include:

- carbon dioxide, $\mathrm{CO}_{2}$,

- methane, $\mathrm{CH}_{4}$,
- ammonia, $\mathrm{NH}_{3}$,

- nitrous oxide, $\mathrm{N}_{2} \mathrm{O}$.

Carbon oxides are formed by incomplete combustion of coal, and thus as a result of oxygen deficiency, as well as by the reaction of low-temperature oxidation of hydrocarbons and their derivatives. The formation of carbon oxides is accompanied by insufficient atomisation and evaporation of fuel as well as insufficient mixing of air and fuel. In diesel engines, the evolution of carbon oxides usually takes place parallel to the formation of soot. It is a colourless and odourless gas dangerous to the human body due to its ease in combining with haemoglobin, which causes hypoxia of the body. Concentrations greater than $660 \mathrm{ppm}$ cause asphyxiation and death (Chłopek, 2012; Tiwary et al., 2018).

Hydrocarbons arise as a result of fuel evaporation, with incomplete or partial combustion. This applies mainly to vehicles with a spark-ignition engine because diesel is less volatile compared to petrol. The oil used by the engine also affects the emission of hydrocarbons. Hydrocarbons react quickly with oxygen and nitrogen compounds, forming peroxides and aldehydes. Aromatic hydrocarbons have a strong toxic effect, while saturated hydrocarbons have a narcotic effect (Chłopek, 2012; Tiwary et al., 2018).

Nitrogen oxides are formed as a result of nitrogen oxidation in the areas of the combustion chamber with a large excess of air and high temperature. Of the many oxygen and nitrogen compounds in the cylinder of the engine, mainly NO oxide is formed, which has a large impact on the toxicity of exhaust gases. The formation of nitric oxide depends on the amount of free oxygen, temperature increase and the highest temperature in the combustion process. Reducing the emission of nitrogen oxides is possible by limiting the rate of heat release, burning a fuel-rich mixture, cooling the combustion chamber and exhaust gas recirculation. Nitric oxide is colourless and odourless, and its density is more than once higher than the air density. Irritating to the respiratory tract, and poisoning with it manifested by weakness and affecting the central nervous system and cardiovascular system (Merkisz, 1999; Amato, 2018).

Sulphur oxides are formed as a result of the combustion of sulphur contained in the fuel. The share of sulphur oxides in the automotive industry is small and amounts to approx. $3 \%$. The reduction of emissions is associated with the use of fuels with low sulphur content (Merkisz, 1999; Amato, 2018).

Solid particles are products that escape from the engine exhaust system and have a liquid or solid consistency. These include irregular carbon collection in the form of soot, absorbed organic compounds from fuel, oil, water and salts, primarily sulphates and nitrates. The composition of solid particles also includes metals originating from the products of abrasion of engine parts and from impurities, or additions of fuel and oil. As the temperature drops, the mass of particulates increases because some hydrocarbons condense. In diesel engines, particulate emissions are a major environmental problem. 
The formation of soot accompanies the diffusion time of fuel combustion. In the case of spark-ignition engines, particulate emissions are not an ecological problem, which results from the lower propensity of gas to form soot. The content in lead and sulphur gas as well as the consumption of engine oil contribute to the formation of solid particles. Particulates are a big threat to organisms. Soot itself is not dangerous, but poisonous substances absorbed by it, i.e. organic compounds, heavy metals, as well as nitrogen and sulphur compounds (Kwiatkowski and Żółtkowski, 2002; Sharma et al., 2018).

Lead compounds are found only in spark-ignition engines powered by ethyl-de-petrol. Lead tetra-acetate added to gasoline increases the octane number. Currently, it is forbidden to add lead compounds to gasoline in the developed economies. Lead accumulates in the liver and fats, damaging the skeletal, hematopoietic, nervous and respiratory systems (Kwiatkowski and Żółtkowski, 2002; Sharma et al., 2018).

\section{Monitoring of pollutant emissions in vehicles}

Emission of pollutants during the operation of motor vehicles is related to both their use in a state of full technical efficiency, as well as inefficient, but able to meet the basic functions of transporting people and goods. This type of damage is the second largest group, immediately after damage directly affecting safety. Typically, this type of damage allows the vehicle to be used without deterioration in driving comfort, without forcing it to be removed, which in turn leads to an increased emission of toxic substances contained in the exhaust (Czech, 2012; Czech, 2013; Madej, 2009).

Constantly increasing requirements related to environmental protection forced vehicle manufacturers to create an effective diagnostic system that would be universal and would enable use in all car brands (Merkisz and Mazurek, 2007). The first research with such a system was carried out in 1988 in the USA and was called OBD (On Board Diagnostic). The task of this system was to constantly monitor all elements of the electronic engine control system. It was characterized by the lack of standardization of diagnostic procedures and error codes and the lack of guaranteed access to diagnostic information. Since its inception, this system has constantly evolved, gaining an increasingly stronger position in the automotive market. By the beginning of 2000 in European Union countries, all newly registered passenger cars with spark ignition engines must have an on-board diagnostic system. In 2004, this obligation began to include cars with self-ignition engines, and since 2006 it must also be placed in newly registered trucks.

The OBD system provides monitoring during vehicle operation of the condition of those elements and car systems that affect the emission of harmful substances into the atmosphere. In the case of defects that lead to an increase in emissions of more than $50 \%$, the user is informed about the emission issue by lighting the MIL control lamp (Kwiatkowski and Żółtkowski, 2002). The monitoring of the operation of supervised vehicle systems that affect emissions is carried out indirectly. The emission of toxic compounds through the exhaust system is determined on the basis of the evaluation of the course of the oxygen sensor signal and other parameters (Merkisz and Mazurek, 2007; Nyberg and Stutte, 2004).

Filipczyk and Madej (2007) carried out the results of research carried out at authorized service stations for motor vehicles. 100 vehicles were tested in the scope of the possibility of using standard exhaust emission measurements, in accordance with the methodology specified in relevant regulations for periodic check tests regarding the technical condition of the engine. The results of measurements of $\mathrm{CO}, \mathrm{CO}_{2}, \mathrm{HC}, \mathrm{O}_{2}$ content, and exhaust smoke level with limit values specified in national regulations and specified by engine manufacturers were compared. The tested cars were produced in different years and were characterized by different courses. The examined damages included cases of engine immobilization, increased fuel consumption and the content of harmful components in the exhaust, damages deteriorating working conditions, causing accelerated wear of components of friction nodes and damage related to the tooling and fixing. The percentage share of individual damage types is shown in the Figure 1. Exhaust emission researches have shown that, most often in cars with a mileage above $100,000 \mathrm{~km}$, despite the legal criteria for emissions met by these cars, the emission of individual exhaust components exceeded the limit values. Among the tested vehicles with spark ignition engines, up to $41 \%$ were out of order due to exceeding the permissible content of harmful components in the exhaust (Filipczyk and Madej, 2007).

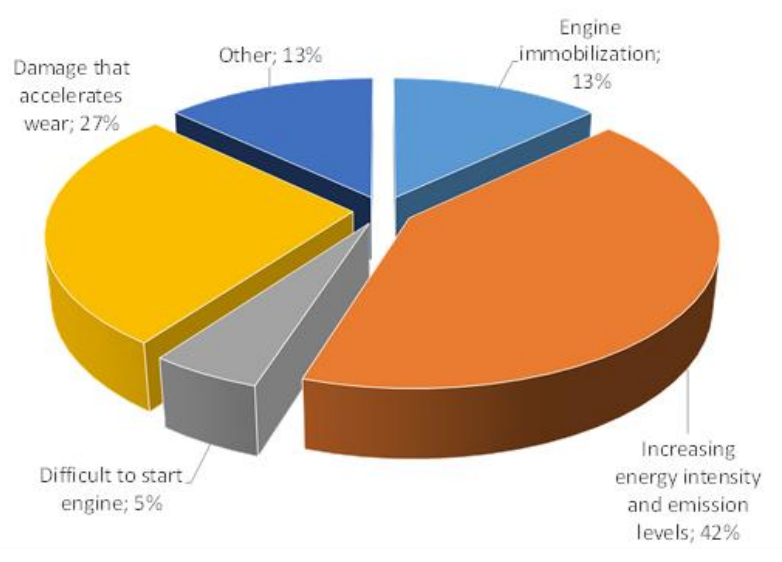

Figure 1. Percentage share of individual damage types (Filipczyk and Madej, 2007)

For reasons of environmental protection, the most important problems of motorization include (Chłopek, 2002):

- protection of the environment against the effects of production and operation of vehicles, consumables and infrastructure of the automotive industry and the management of used elements,

- material consumption, energy consumption, costs of production and operation of vehicles, costs of managing 
used vehicles, consumables and motorization infrastructure,

- operational vulnerability of vehicles,

- vehicle reliability,

- durability of vehicles.

\section{Ways to reduce the emission of pollutants emitted from internal combustion engines}

The reduction of pollutant emissions from engines can be obtained through changes (Chłopek, 2002; Merkisz, 1999; Merkisz et al., 2012):

- regulatory ones, which do not require structural changes, are limited to the regulation of the power supply system,

- constructional,

- in the type and properties of fuels, fuel additives and other consumables.

Furthermore, the reduction of the harmfulness of emission of pollutants from engines to the environment consists in (Chłopek, 2002; Chłopek, 2012; Merkisz, 1999; Kwiatkowski and Żółtkowski, 2002; Merkisz et al., 2012):

- limiting the formation of harmful substances,

- increasing the overall efficiency of the engine,

- purifying of exhaust gases.

Solutions used in spark-ignition engines to reduce pollutant emissions are (Chłopek, 2002; Merkisz, 1999):

- increasing the compression ratio,

- using injection power systems,

- application of an intake system using variable geometric properties,
- use of plasma, laser and photochemical ignition,

- exhaust gas recirculation to reduce the emission of nitrogen oxides,

- reducing the content of ring hydrocarbons, lead compounds and sulphur, increasing the content of isoalkanes in new fuels,

- integrated electronic measurement, control and diagnosis systems,

- catalytic purification of exhaust gases.

Solutions used in self-ignition engines to reduce pollutant emissions are (Chłopek, 2002; Merkisz, 1999):

- delay in the start of injection,

- injection pressure regulation - increase injection pressure,

- fuel dose adjustment,

- multistage recharging with fuel cooling,

- exhaust gas recirculation and cooling,

- increasing the cetane number, reducing the sulphur content and ring hydrocarbons in new fuels,

- catalytic methods of exhaust cleaning.

In the European Union, EURO standards are in force, which regulate emission limits for harmful substances for motor vehicles. The regulations are an important element of the Clean Air for Europe program aimed at reducing air pollution (Merkisz et al., 2012; Regulation (EC) No 715/2007; Directive 98/69/EC; Council Council Directive; Directive 94/12/EC). The successive EURO standards (EURO $1,2, \ldots, 6)$ introduced in subsequent years tightens the requirements for maximum emission values of harmful substances, which can be seen in Tables 1 and 2 .

Table 1. Values of emission of harmful substances for new vehicles with a spark-ignition engine (Regulation (EC) No 715/2007; Directive 98/69/EC; Council Council Directive; Directive 94/12/EC)

\begin{tabular}{ccccccc}
\hline & $\begin{array}{c}\text { CO }[\mathrm{mg} / \mathrm{kg}] \\
\text { (carbon } \\
\text { oxides) }\end{array}$ & $\begin{array}{c}\text { THC [mg/kg] (total } \\
\text { hydrocarbons) }\end{array}$ & $\begin{array}{c}\text { NMHC [mg/kg] (non- } \\
\text { methane hydrocarbons) }\end{array}$ & $\begin{array}{c}\text { NOx [mg/kg] } \\
\text { (nitrogen oxides) }\end{array}$ & $\begin{array}{c}\text { THC + } \\
\text { NOX } \\
{[\mathrm{mg} / \mathrm{kg}]}\end{array}$ & $\begin{array}{c}\mathrm{PM}[\mathrm{mg} / \mathrm{kg}] \\
\text { (particulate } \\
\text { matter) }\end{array}$ \\
\hline EURO 4 & 1000 & 100 & - & 80 & - & - \\
\hline EURO 5 & 1000 & 100 & 68 & 60 & - & 5 \\
\hline EURO 6 & 1000 & 100 & 68 & 60 & - & 5 \\
\hline
\end{tabular}

Particular emphasis in EURO regulations has been placed on solid particles. To the limit values for vehicles with compression-ignition engines, the one for vehicles with a spark-ignition engine have been added. This only applies to engines with direct fuel injection. Nitrogen oxides are next contamination with strict requirements. The EURO 5 and 6 regulations are the same for spark-ignition engines. However, they decreased by $25 \%$ compared to EURO 4. Whereas the difference between EURO 4 and 6 is almost $70 \%$ for self-ignition engines. The emission of total hydrocarbons and non-methane hydrocarbons was also reduced for vehicles with a spark-ignition engine. The total emissions of hydrocarbons and nitrogen oxides for self-ignition engines were also reduced (Merkisz et al., 2012; Regulation (EC) No 715/2007; Directive 98/69/EC; Council Council Directive; Directive 94/12/EC). Increased requirements related to reducing the emission of toxic substances released into the atmosphere by motor vehicles and constantly decreasing fuel resources cause that engineers are forced to search for new propulsion systems in the area of more efficient use of fuel energy. For this reason, car concerns are looking for new designs such as hybrid or fully electric drive. Hybridisation of the drive system is based on the cooperation of specific energy sources in the vehicle in such a way as to obtain a high efficiency drive system with ideal operating indices. At the same time, there must be lower fuel consumption and reduced emissions of toxic substances. In addition to fully electrically powered vehicles, primarily combustion engines that interact with electrical machines are tested. The results show that these types of propulsion systems are the most common in urban traffic, and within 20 years on 
the car market there will be about $10 \%$ of vehicles that use both internal combustion engines and electric motors. The increasing awareness of people related to the issue of environmental protection, i.e. the need to reduce harmful substances emitted to the environment, causes the growing sale of hybrid and fully electric vehicles (Merkisz et al., 2012; Regulation (EC) No 715/2007; Directive 98/69/EC; Council Council Directive; Directive 94/12/EC).

Table 2. Values of emission of harmful substances for new motor vehicles with self-ignition engine (Regulation (EC) No 715/2007; Directive 98/69/EC; Council Council Directive; Directive 94/12/EC)

\begin{tabular}{ccccccc}
\hline & $\begin{array}{c}\text { CO [mg/kg] } \\
\text { (carbon oxides) }\end{array}$ & $\begin{array}{c}\text { THC [mg/kg] (total } \\
\text { hydrocarbons) }\end{array}$ & $\begin{array}{c}\text { NMHC [mg/kg] (non- } \\
\text { methane hydrocarbons) }\end{array}$ & $\begin{array}{c}\text { NOx [mg/kg] } \\
\text { (nitrogen oxides) }\end{array}$ & $\begin{array}{c}\text { THC + NOx } \\
{[\mathrm{mg} / \mathrm{kg}]}\end{array}$ & $\begin{array}{c}\mathrm{PM}[\mathrm{mg} / \mathrm{kg}] \\
\text { (particulate } \\
\text { matter) }\end{array}$ \\
\hline EURO 4 & & & & & & \\
\hline EURO 5 & 500 & - & - & 180 & 230 & 5 \\
\hline EURO 6 & 500 & - & - & 80 & 170 & 5 \\
\hline
\end{tabular}

In hybrid vehicles, it is possible to keep toxic exhaust gas components low by using oxidation-reducing catalytic converters and engines with large displacement. Vehicles of this type are also characterized by reduced fuel consumption and high power of the entire system resulting from the arrangement of individual components (e.g. combustion engine and electric). In the European test on vehicles with conventional propulsion, internal combustion engines work in the area of low partial load, which is not suitable for reasons of efficiency. The low-load area of the internal combustion engine in a car with a parallel hybrid drive can be converted into an electric drive, in which the energy usually comes from the generator operation of the electric motor. In this case, the displacement of the engine's working field takes place in the direction of greater load and high efficiency range, which is why more electricity is obtained for separation. Higher energy flow worsens the durability of the batteries, which forces the use of new solutions, enabling both reduction of carbon dioxide emissions and energy expenditure. For hybrid drives with separated power, the combustion engine's operating area is small, because it depends on the speed of rotation, and the entire drive system works optimally due to energy consumption. In this case, due to the simultaneous operation of the electric motor and the current generator, the energy flow and the continuous use of energy accumulated in the batteries is smaller compared to the parallel hybrid drive (Bosch, 2010; Michałowski and Ocioszyński, 1989).

Considering the huge air pollution in large urban agglomerations, there are concepts of closing city centres for the movement of individual vehicles (not belonging to the group of public transport vehicles and municipal services). There are also voices strongly supporting another type of transport, including metro or bicycle communication (Jacyna et al., 2015; Jacyna et al., 2017).

Currently, there are standards in the European Union regarding the permissible values of particulate matter, ozone, nitrous oxide, carbon monoxide, lead emissions and other pollutants that may affect the ecosystem and human. The basic act of the European Union law regarding the protection of atmospheric air is Directive 2008/50/EC of the European Parliament and of the Council of 21 May 2008 on ambient air quality and cleaner air for Europe (Directive 2008/50/EC). The Directive contains measures aimed at:
- defining air quality objectives that will prevent or reduce harmful effects on the environment and human health,

- assessment of air quality in EU countries according to common methods and criteria,

- obtaining information on air quality, helpful in combating air pollution, monitoring long-term trends and improving air quality,

- providing public information about air quality,

- protection of places where air is of good quality and improvement in other areas,

- promoting close cooperation between EU Member States in reducing air pollution.

The changes introduced in European Union law are systematically implemented into Polish law.

The work (Act of 27 April, 2001) is the most important Polish document regulating the issues of environmental protection.

\section{Monitoring of hazards related to air pollution}

\subsection{Meteorological conditions}

The spread of pollutants in atmospheric air is shaped by the following processes (Foszcz et al., 2006; Holnicki-Szulc, 2006; Morawska-Horawska and Kuroś, 1992; Tumidajski et al., 2009; Tumidajski et al., 2007):

- transport by wind,

- mixing with the surrounding air (diffusion),

- chemical changes,

- removing from the atmosphere through dry subsidence on the ground or leaching in the clouds and atmospheric precipitation,

- the interaction of pollutants,

- photochemical reactions.

The air quality in a given area is largely dependent on pollutant emissions and meteorological conditions. Emission is a major factor in the occurrence of air pollution, but its concentration depends primarily on meteorological conditions. Meteorological factors can affect air quality by controlling emissions and affecting the movement of pollutants. Emission control determines the indirect impact of meteorological conditions on certain types of emissions. The drop in air temperature and the increase in wind speed 
cause an increase in heat demand in residential rooms and workplaces. Due to the use of combustion processes by heating systems in order to obtain heat, the number of fuels burned causing the emission of pollutants to the environment increases. Meteorological conditions also affect some social behaviours. No precipitation, high sunshine, especially in summer, have an impact on the growth of traffic especially on Saturdays and Sundays. Good weather conditions also affect the increase of emissions in the autumn related to gardening work, which often involves the burning of field waste. The cases given are of course one of many situations when meteorological conditions affect the change in pollution concentration. It is estimated that meteorological conditions determine the size of air pollution by as much as 70\% (Air Quality Forecasting System).

In the problem of air pollution, the processes occurring in the troposphere as a layer adjacent to the earth's surface are of particular importance. The Troposphere is a layer in which weather is created, variable wind, cloudy, atmospheric pressure and precipitation patterns. It is to this layer that the largest amount of atmospheric air pollutants is emitted (Vallero, 2014).

The formation of the Earth's surface affects the movement of the air flowing over it and the exchange of heat between the surface of the earth and the atmosphere. Heat exchange processes affect temperature changes along with the height in the boundary layer as well as vertical movements and mixing processes. In the free layer, on the other hand, the impact of large-scale pressure and circulation systems predominates. Wind speed and direction are the most important among these factors. Wind speed influences the speed of pollution movement, while the direction determines the direction of transport. Low wind speeds and wind noise cause deterioration of air quality as a result of reduced horizontal ventilation of atmospheric air. The temperature of the atmospheric air, similarly to the other meteorological factors, influences the change in the concentration of pollutants. High temperatures occurring in the summer period may reduce the vertical gradient, which promotes smog situations. The thermal structure of the boundary layer of the atmosphere (convective, inversion) determines the state of the atmosphere's equilibrium, i.e. the atmosphere's ability to stimulate and inhibit vertical movements, which is indirectly related to the conditions of air mixing. The fragile balance of the atmosphere is enhanced by vertical mixing processes. Constant equilibrium, which accompanies the construction of thermal inversion, inhibits vertical movements. An indifferent balance is treated as an intermediate state between the equilibrium and constant equilibrium occurring, e.g. in strong wind or rainfall. Precipitation, mainly rains, depending on their intensity and duration, are washed out by some air pollutants, including dust. Meteorological data sets are necessary data for determining the dispersion of pollutants in the atmosphere and for calculating the substance's emission's field (Chłopek, 2002; Chłopek, 2012).

\subsection{Air monitoring}

Regardless of the policy adopted to counteract the emission of harmful substances into the atmosphere, among others by road vehicles, monitoring and predicting their level is extremely important.

In Poland, air quality studies have been conducted for many years. Based on the collected results, air quality assessments are carried out. According to European Union law, the data received is forwarded to the European Commission and made available to the public. When joining the European Union, Poland was obliged to adapt the atmospheric air monitoring system to the EU requirements (Merkisz et al., 2012).

The condition of atmospheric air quality in Poland is monitored as part of state environmental monitoring, and the responsibility for its conduct was entrusted to the Environmental Protection Inspection. According to the regulations, air concentrations of sulphur dioxide, nitrogen oxides, particulate matter $\mathrm{PM}_{10}$, lead (in $\mathrm{PM}_{10}$ ), carbon monoxide, ozone and benzene are monitored in the air. The air is assessed outside the buildings throughout the country. To accurately monitor the quality of atmospheric air, Poland has been divided into several dozen zones (Figure 2). As part of air monitoring, Provincial Inspectorates for Environmental Protection are responsible for monitoring and assessment of air quality in particular zones in the area of a given voivodship. On the basis of the data received, at least every five years an assessment of the air quality is made, based on which the voivodship monitoring system is established and the necessary changes are introduced to improve the monitoring and protection of the atmospheric air. For each zone, an air assessment is made every year, based on which, if the air quality standard is not met, the voivode is obliged to implement an air protection program in this zone (Chief Inspectorate of Environmental Protection, Zones).

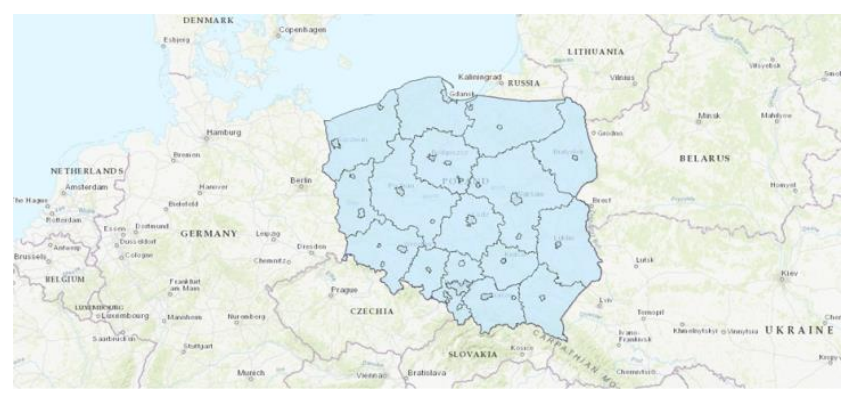

Figure 2. Zones where air quality is assessed (Chief Inspectorate of Environmental Protection, Zones)

The air quality is controlled using an extensive monitoring system. This system carries out constant measurements, observations and assessments of air pollution in a given area. In addition to the registration of pollutants, the system collects information on meteorological factors such as temperature, wind direction, wind speed, solar radiation intensity, relative humidity, atmospheric pressure and others. All measurements are recorded in a time interval equal to 60 minutes (Chief Inspectorate of Environmental Protection, Zones). 
Based on the recorded air quality data, an assessment is made by comparing the recorded data with established standards expressing acceptable levels of selected substances in the air. Permissible levels differ in some areas, for example health resorts, for which there are stricter rules (Chief Inspectorate of Environmental Protection, Zones).

\section{Modelling of air pollution}

Modelling is a process of simplified reproduction of reality. The language of mathematics is used to describe the relationships, phenomena, or processes observed in the real environment. The resulting simplification of models in relation to reality does not result in its less usefulness compared to research on real objects. Often, the applied simplifications affect a more understandable operation, and the area of possible application becomes much wider due to this (Birkes and Dodge, 1993). Accurate and complex models are most often used in very limited situations (Hoffman, 2004; Hoffman, 2013).

There are numerous chemical changes in the air to which combustion gases enter, such as the oxidation of organic compounds, the production of free radicals, the transformation of oxygen compounds, etc. As a result of physical changes, i.e. diffusion, deposition, the concentration of pollutants also changes. It should be noted that often the effects of changes are opposed (Vallero, 2014). As a result of the complex nature of the changes, it is difficult to develop mathematical models that allow working at the appropriate level of accuracy.

Mathematical modelling distinguishes deterministic and stochastic models. For deterministic models, there is an unambiguous assignment in line with the analytical modelling function. The specified value of inputs corresponds to one output. In stochastic models, there are also random variables. Therefore, the probability aspect appears in the answer (Ostasiewicz, 1999).

During research, it is often the case that you do not have full knowledge of the phenomenon being studied, but you have a limited set of observations. In such cases, predictive models that enable the extraction of knowledge about the studied dependencies through the analysis of available information prove to be useful. Models of this type are mainly built based on the regression analysis method (Hoffman, 2004; Hoffman, 2013).

Statistical models are used to determine empirical connections between pollutant concentrations and meteorological parameters as well as short-term forecasting. Concentrations of air pollutants are random variables, and their values in equal successive time intervals - as it happens in the concentration monitoring process - form time series constituting a stochastic process from an infinite population of random variables.

It should be noted here that the concentration of pollutants as a random variable has the appropriate function of probability distribution density and the occurrence of autocorrelation. Both the form of distribution and autocorrelation are subject to daily and seasonal variability
(Foszcz et al., 2006; Holnicki-Szulc, 2006; MorawskaHorawska and Kuroś, 1992; Tumidajski et al., 2009; Tumidajski et al., 2007). In the literature there are attempts to systematize models according to various criteria, including:

- the spatial scale of the model,

- the time scale of the model,

- the type of pollution,

- the destination of the model.

There is also a classification due to the mathematical basis of the models, according to which Euler and Lagrange models are distinguished. For Euler-type models, the spread of pollution is described in relation to the system associated with the Earth, while in the case of Lagrange models in the system associated with moving air masses. A special group of Gaussian models is also used, which are a simplification of the Lagrange method. The mentioned models differ in the description of processes related to the spread of pollutants in the air, that is, the description of transport, diffusion, chemical changes and removal of pollutants from the atmosphere. For the most accurate models there are high requirements regarding the number and quality of data (Foszcz et al., 2006; Holnicki-Szulc, 2006; Morawska-Horawska and Kuroś, 1992; Tumidajski et al., 2009; Tumidajski et al., 2007).

\section{The concept of neural modelling of air pollution}

Due to the characteristics of artificial neural networks, it seems that they are the right tool to meet the challenge in the task of modelling air pollution.

The most important advantages of such models used are the suitability for modelling any non-linearities, high resistance to interference, parallel processing of information, the ability to learn, the ability to adapt and self-organization, the ability to generalize knowledge in which they were provided (Hu and Hwang, 2002; Korbicz et al., 2002; Nałęcz et al., 2000; Osowski, 2013; Tadeusiewicz, 1993; Tadeusiewicz et al., 2014; Siwek and Osowski, 2016; Witkowska, 2002).

In the operation of the neural network, its biological inspiration is used, which is the human brain. The basic element of artificial neural networks are artificial neurons. They are not a faithful copy of a biological neuron, but an element that fulfils similar functions. A comparison of the artificial and biological neuron is shown in Figure 3 (Tadeusiewicz, 1993).

The signal given to the neuron's inputs is multiplied by appropriately selected weighting factors. These scales correspond to the strength of synaptic connections in the biological neuron. Then, these signals are added together and the level of neuron activation is determined. 

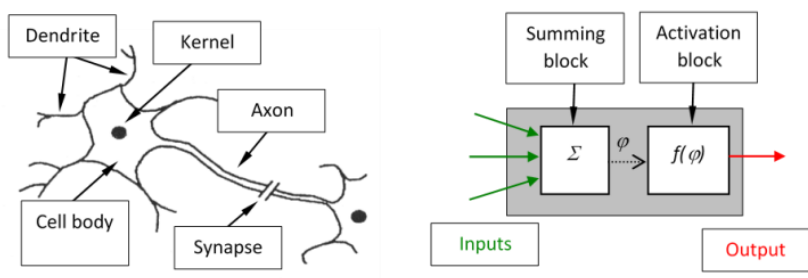

Figure 3. The structure of the biological neural cell and the structure of the artificial neuron (Tadeusiewicz, 1993)

In the biological neuron, the summation block corresponds to the cell body, and the $\varphi$ signal it generates corresponds to the membrane potential of the cell. Since the actual biological neurons are nonlinear, the function $f(\varphi)$ called the activation function has been introduced in artificial neurons. It defines a non-linear relationship between the resultant neuron stimulation signal $\varphi$ and the output signal that is the neuron's response to the input signals. Depending on the form of the assumed function $f(\varphi)$, the neuron response can be considered as binary or bipolar ( $\mathrm{Hu}$ and Hwang, 2002; Korbicz et al., 2002; Nałęcz et al., 2000; Osowski, 2013; Tadeusiewicz, 1993; Tadeusiewicz et al., 2014; Siwek and Osowski, 2016; Witkowska, 2002).

A set of many non-linear neurons connected with each other and in parallel - forms a neural network. Unidirectional layered neural networks are most commonly used. Multi Layer Perceptrons (MLP) belongs to this type of network. This network consists of an input layer, a layer or several hidden layers and an output layer (Hu and Hwang, 2002; Korbicz et al., 2002; Nałęcz et al., 2000; Osowski, 2013; Tadeusiewicz, 1993; Tadeusiewicz et al., 2014; Siwek and Osowski, 2016; Witkowska, 2002). The entrance layer consists of so many neurons from how many data one pattern is built up. Since in most cases the only role of neurons in the input layer is to introduce external signals to the network without processing them, this layer is usually not counted into the number of network layers (Tadeusiewicz, 1993). The output layer is composed of the number of neurons that the number of classes has to recognize a given neural network or from one neuron in the case of approximation tasks. Layers of neurons lying between the input and the output of the network are called hidden layers. Neurons lying in such layers cannot be directly observed either from the inputs or from the outputs of the neural network. Neurons in adjacent layers are connected according to the peer-to-peer principle, and each combination is assigned a properly selected weight. The knowledge contained in the neural network is represented by its structure and values of weights between connected neurons. An exemplary diagram of the structure of the MLP neural network is shown in Figure 4 (Tadeusiewicz et al., 2014).

If you want to use artificial neural network, you should specify the number of hidden layers, the number of neurons in each layer, the type of activation function and the value of weights between individual neuron connections. The literature indicates the lack of rules regarding the selection of these parameters and indicates the need to establish them by experimental method - trials and errors (Hu and Hwang, 2002; Korbicz et al., 2002; Nałęcz et al., 2000; Osowski, 2013; Tadeusiewicz, 1993; Tadeusiewicz et al., 2014; Siwek and Osowski, 2016; Witkowska, 2002).

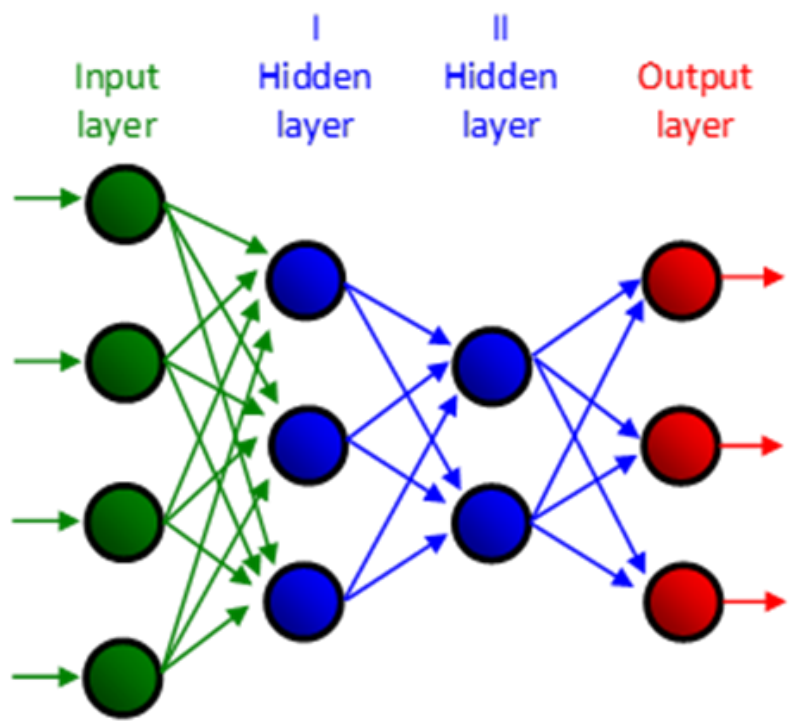

Figure 4. Diagram of the structure of a multi-layer one-way network (Tadeusiewicz et al., 2014)

In practice, the most-used is a low-complex network containing up to two layers hidden, which facilitates and shortens the learning process of such models (Witkowska, 2002).

A network with too few neurons may not be able to reflect in its structure all the possible nuances of the solved task. Too many hidden layers lead to a significant deterioration of the learning process, as the network tries to reproduce the excess of details. The excess of neurons in hidden layers leads to the effect of "learning by heart", i.e. the loss of the ability to generalize knowledge (Tadeusiewicz, 1993; Tadeusiewicz et al., 2014).

The weight value between connected neurons is determined in the neural network learning process. There are two types of network learning: with and without a teacher. In the first case of the neural network, learning patterns and correct answers to them are repeatedly shown. In the second case, however, only learning data is shown, and the network has the task of setting the values on its outputs.

To properly carry out the learning process, a well-chosen and numerous set of patterns is needed ( $\mathrm{Hu}$ and Hwang, 2002; Korbicz et al., 2002; Nałęcz et al., 2000; Osowski, 2013; Tadeusiewicz, 1993; Tadeusiewicz et al., 2014; Siwek and Osowski, 2016; Witkowska, 2002). The set of patterns is usually divided into a part for learning the network and a set intended for network validation. In the literature, this collection is also called the checking set. Because the validation set in a sense participates in the network learning process, its independence as a tool evaluating the network is undermined. Therefore, in addition, a test set is separated, by means of which the operation of the neural network is checked once. This set is thus used for the final 
control of the correctness of the neural model operation, and the result has no effect on changing the weights between connections.

Changes in the size of weight coefficients for individual connections between neurons are determined based on the rules (Hu and Hwang, 2002; Korbicz et al., 2002; Nałęcz et al., 2000; Osowski, 2013; Tadeusiewicz, 1993; Tadeusiewicz et al., 2014; Siwek and Osowski, 2016; Witkowska, 2002). The applied learning rules and their variations is an enormous number. The algorithm of backward error propagation is the most popular artificial neural network paradigm.

Gately (1995) recommends using the neural networks to work according to the scheme:

- stage I: defining the task,

- stage II: collection of a data set,

- stage III: pre-processing of data (pre-processing),

- stage IV: establishing minimum and maximum values of patterns,

- stage V: division of data into a training and testing set,

- stage VI: selection of network architecture,

- stage VII: selection of the learning algorithm,

- stage VIII: network learning process,

- stage IX: network testing process.

In the literature can be found very interesting studies on this subject, including (Hoffman, 2004; Hoffman, 2013; Hoffman and Jasiński, 2009). Hoffman (2004) presents the results of his research devoted to the determination of $\mathrm{O}_{3}$, $\mathrm{NO}_{x}, \mathrm{NO}_{2}, \mathrm{NO}, \mathrm{SO}_{2}, \mathrm{CO}, \mathrm{PM}$ concentrations in selected cities of the Silesian Voivodship - in Zabrze and Kędzierzyn Koźle. In the first case, it uses data from 1994-1997 and in the second from 1994-1999. On the other hand, Hoffman (2013) analyses the levels of $\mathrm{O}_{3}, \mathrm{NO}, \mathrm{NO}_{2}, \mathrm{CO}, \mathrm{SO}_{2}, \mathrm{PM}$ concentrations in selected eight cities of the Mazowieckie Province and presents them in detail for Widzew and Radom. The scope of the data covered the years 2004-2010. In addition to the goal of determining the use of neural networks for regression modelling of pollutant concentrations, the aim of the research was also to find and determine the strength of interrelationships between standard variables measured in continuous air monitoring. It should be noted that some of the dependencies have a hidden character that can be revealed in non-linear neural models. Both linear and nonlinear models were investigated. In his publications, the author also points to the interesting problem of how to assess the quality of models. The presented test results indicate different results depending on the chosen measure of error. An extremely important problem concerns the completeness of measurement data. Hoffman (2009) presents ways to deal with this type of problems.

Because in the literature there was no definite answer to the questions about how to build neural models to always obtain the lowest error values, it seems appropriate to conduct research on this subject. It should be noted that the results of research carried out in the field of determining concentrations of contamination using neural networks indicate that it is impossible to choose one universal way to create neural models for all possible cases.

\section{Conclusions}

The classification of environmental hazards by motorization is related to the characteristics of individual interactions. In the case of polluting emissions, hazards depend on the type of substances emitted and on the quantities characterizing the amount and intensity of pollution entering the environment.

Looking at the aforementioned problems from the perspective of the inhabitants of large urban agglomerations, issues related to the operation of means of transport and the effect in the form of excessive air pollution by fumes acquire particular importance. This is undoubtedly due to congestion in all major cities.

Undoubtedly, components of exhaust gases emitted by cars have a particularly unfavourable effect on the natural environment, including $\mathrm{CO}, \mathrm{NO}_{\mathrm{x}}$, and $\mathrm{PM}$. It should be noted, however, that from year to year, the increasingly stringent standards that the automotive industry must meet. This refers to the Euro standards, including the currently valid Euro 6 standard. Also in the field of air pollution monitoring, the applicable regulations clearly define what and how to monitor.

Regardless of the measures taken so far to reduce air pollution in urban agglomerations, much remains to be done. The basic question, and perhaps even necessary in further actions, is the possibility of predicting air pollution based on various factors affecting them. For this purpose, it would certainly be useful to develop an appropriate mathematical model. Unfortunately, at the moment, it has not been possible to develop a universal model that would be suitable for use in all research problems. It should be remembered that each model is only an approximation of reality, although in the case of its correct construction it gives a correct view of the real research problem.

As indicated in the article, it seems extremely interesting to be able to use artificial intelligence methods, including artificial neural networks.

\section{Acknowledgements}

The scientific research was funded by the statute subvention of Czestochowa University of Technology, Faculty of Infrastructure and Environment - BS/PB/400-301/20.

\section{References}

Act of 27 April (2001), Environmental protection law (Dz. U. 2001 nr 62 poz. 627).

Air Quality Forecasting System in zones and agglomerations of the Slaskie Voivodeship, Review of climatic factors affecting air quality in the Slaskie Voivodeship, Available at: http://spjp.katowice.pios.gov.pl/klimat.aspx.

Amato F. (ed.) (2018), Non-Exhaust Emissions. An Urban Air Quality Problem for Public Health. Impact and Mitigation Measures, Academic Press, Elsevier. 
Birkes D. and Dodge Y. (1993), Alternative methods of regression, Wiley-Interscience Publication, New York.

Bosch (2010), Hybrid drives, fuel cells and alternative fuels, Technical guide, WKiL Press, Warsaw.

Chief Inspectorate of Environmental Protection, Zones, available at: http://powietrze.gios.gov.pl/pjp/maps/zones.

Chłopek Z. (2002), Protection of the natural environment, WKiL Press, Warsaw.

Chłopek Z. (2012), Ecological aspects of motorization and road safety, Warsaw University of Technology Publisher, Warsaw.

Council Council Directive of 26 June 1991 amending Directive $70 / 220 / E E C$ on the approximation of the laws of the Member States relating to measures to be taken against air pollution by emissions from motor vehicles (91 /441 /EEC), Official Journal of the European Union, L. 242, 30.8.91.

Czech P. (2012), Determination of the course of pressure in an internal combustion engine cylinder with the use of vibration effects and radial basis function - preliminary research, 12th International Conference on Transport Systems Telematics (TST), Katowice, Poland, OCT 10-13, 2012, Telematics in the Transport Environment, Communications in Computer and Information Science, 329, 175-182.

Czech P. (2013), Diagnosing a car engine fuel injectors' damage, 13th International Conference on Transport Systems Telematics (TST), Katowice, Poland, OCT 23-26, 2013, Activities of Transport Telematics, Communications in Computer and Information Science, 395, 243-250.

Directive 2008/50/EC of the European Parliament and of the Council of 21 May 2008 on ambient air quality and cleaner air for Europe (OJ L 152, 11.6.2008, p. 1).

Directive 94/12/EC of the European Parliament and the Council of 23 March 1994 relating to measures to be taken against air pollution by emissions from motor vehicles and amending Directive 70/220/EEC, Official Journal of the European Union, L. $100,19.4 .94$.

Directive 98/69/EC of the European Parliament and of the Council of 13 October 1998 relating to measures to be taken against air pollution by emissions from motor vehicles and amending Council Directive 70/220/EEC, Official Journal of the European Union, L. 350, 28.12.98.

Filipczyk J. and Madej H. (2007), Problems of diagnosing automotive internal combustion engines in terms of emissions of toxic compounds, XXXIV Symposium Diagnostics of Machines, Wegierska Gorka.

Foszcz D., Niedoba T., Siewior J. and Tumidajski T. (2006), Stochastic models of air pollutants spreading as the method of emission amount management allowing elimination of high pollution concentrations in ecosystems, Environmental Management Accounting and Cleaner Production Conference, Graz, Austria.

Gately E. (1995), Neural Networks for Financial Forecasting. Top Techniques for Designing and Applying the Latest Trading Systems, Wiley Trader's Adventage, New Jersey, USA.

Hoffman S. (2004), Application of neural networks in regression modeling of air pollution concentrations, Publishing House of Czestochowa University of Technology, Czestochowa.

Hoffman S. (2013), Modeling of the level of immission at air monitoring stations using perceptron neural networks, Publishing House of Czestochowa University of Technology, Czestochowa.
Hoffman S. and Jasiński R. (2009), Filling in missing data on air monitoring systems, Publishing House of Czestochowa University of Technology, Czestochowa.

Holnicki-Szulc P. (2006), Models of atmospheric pollution propagation in application to control and control of environmental quality, EXIT Academic Publishing House, Warsaw.

Hu Y.H. and Hwang J.N. (2002), Handbook of neural network signal processing, CRC Press.

Jacyna M., Golebiowski P. and Szczepanski E. (2015), City transport service model taking into account different means of transport, 19th International Scientific Conference on Transport Means Location, Kaunas University of Technology, Kaunas, Lithuania, October 22-23.

Jacyna M., Wasiak M., Lewczuk K. and Karoń G. (2017), Noise and environmental pollution from transport: decisive problems in developing ecologically efficient transport systems, Journal of Vibroengineering, 19(7), 5639-5655.

Korbicz J., Kościelny J., Kowalczuk Z. and Cholewa W. (2002), Process diagnostics. Models. Methods of artificial intelligence. Applications, WNT Press, Warsaw.

Krzywonos M., Borowski P.F., Kupczyk A. and ZabochnickaŚwiątek M. (2014), Abatement of $\mathrm{CO}_{2}$ emissions by using motor biofuels, Przemysł Chemiczny, 93(7), 1124-1127.

Kwiatkowski K. and Żółtkowski B. (2002), Ecological aspects of the impact of diesel engines, Diagnostyka, 26, 107-110.

Madej H. (2009), Diagnosis of mechanical damage in combustion engines masked by electronic control devices, Publisher of the Institute for Sustainable Technologies, Katowice-Radom.

Merkisz J. (1999), Ecological problems of internal combustion engines, Publisher of Poznan University of Technology, Poznan.

Merkisz J. and Mazurek S. (2007), On-board diagnostic systems for vehicles, WKiL Press, Warsaw.

Merkisz J., Pielecha J. and Radzimirski S. (2012), Emissions of automotive pollution in the light of new European Union regulations, WKiL Press, Warsaw.

Michałowski K. and Ocioszyński J. (1989), Motor vehicles with electric and hybrid drive, WKiL Press, Warsaw.

Morawska-Horawska M. and Kuroś E. (1992), The specificity of $\mathrm{SO}_{2}$ emission volumes in the GOP area and the possibilities of forecasting average daily $\mathrm{SO}_{2}$ concentrations, Ochrona Powietrza i Problemy Odpadów, 6, 148-150.

Nałęcz M., Duch W., Korbicz J., Rutkowski L. and Tadeusiewicz R. (2000), Neural networks, Biocybernetics and Biomedical Engineering, Volume 6, EXIT Academic Publishing House, Warsaw.

Nyberg M. and Stutte T. (2004), Model based diagnosis of the air path of an automotive diesel engine, Control Engineering Practice, 12, 513-525.

Osowski S. (2013), Neural networks for information processing, Warsaw University of Technology Publishing House, Warsaw.

Ostasiewicz W. (ed.) (1999), Statistical methods of data analysis, Publisher of the University of Economics in Wroclaw, Wroclaw.

Regulation (EC) No 715/2007 of the European Parliament and of the Council of 20 June 2007 on type approval of motor vehicles with respect to emissions from light passenger and commercial vehicles (Euro 5 and Euro 6) and on access to vehicle repair and maintenance information, Official Journal of the European Union, L. 171, 29.6.2007. 
Sharma N., Agarwal A.K., Eastwood P., Gupta T. and Singh, A.P. (eds.) (2018), Air Pollution and Control, Energy, Environment, and Sustainability, Springer, Singapore.

Siwek K. and Osowski S. (2016), Data mining methods for prediction of air pollution, International Journal of Applied Mathematics and Computer Science, 26(2), 467-478.

Tadeusiewicz R. (1993), Neural networks, Academic Publishing House, Warsaw.

Tadeusiewicz R., Chaki R. and Chaki N. (2014), Exploring Neural Networks with C\#, CRC Press, Taylor \& Francis Group, Boca Raton.

Tiwary A., Williams I. and Colls J. (2018), Air Pollution. Measurement, Modelling and Mitigation, CRC Press.

Tumidajski T., Foszcz D., Niedoba T. and Siewior J. (2009), Stochastic models of air pollution in industrial agglomerations, Rocznik Ochrony Srodowiska, 11(1), 543554.

Tumidajski T., Foszcz D., Niedoba T., Siewior J. (2007), Assessment of inflow of air pollutants by various statistical methods, Zeszyty Naukowe Wydzialu Budownictwa i Inzynierii Srodowiska, Seria: Inzynieria Srodowiska, The Koszalin University of Technology, 23, 219-230.

Vallero D. (2014), Fundamentals of Air Pollution, Elsevier, Academic Press, Oxford, UK.

Witkowska D. (2002), Artificial neural networks and statistical methods. Selected financial issues, C.H. Beck Press, Warsaw.

Zabochnicka-Świątek M. (2015), Support for $\mathrm{CO}_{2}$ capture using biotechnology, In: Oxygen combustion for pulverized and fluidized bed boilers integrated with $\mathrm{CO}_{2}$ capture. Experiences from pre-installations and perspectives for demonstration installations, Nowak W., Ściążko M. and Czakiert T. (eds.), Publishing House of Czestochowa University of Technology, Czestochowa, pp. 196-212. 